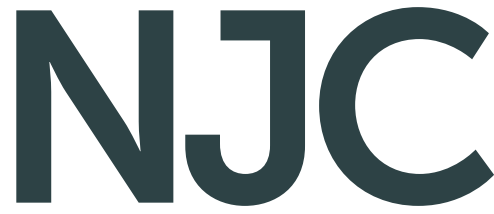

A journal for new directions in chemistry

New Journal of Chemistry www.rsc.org/njc

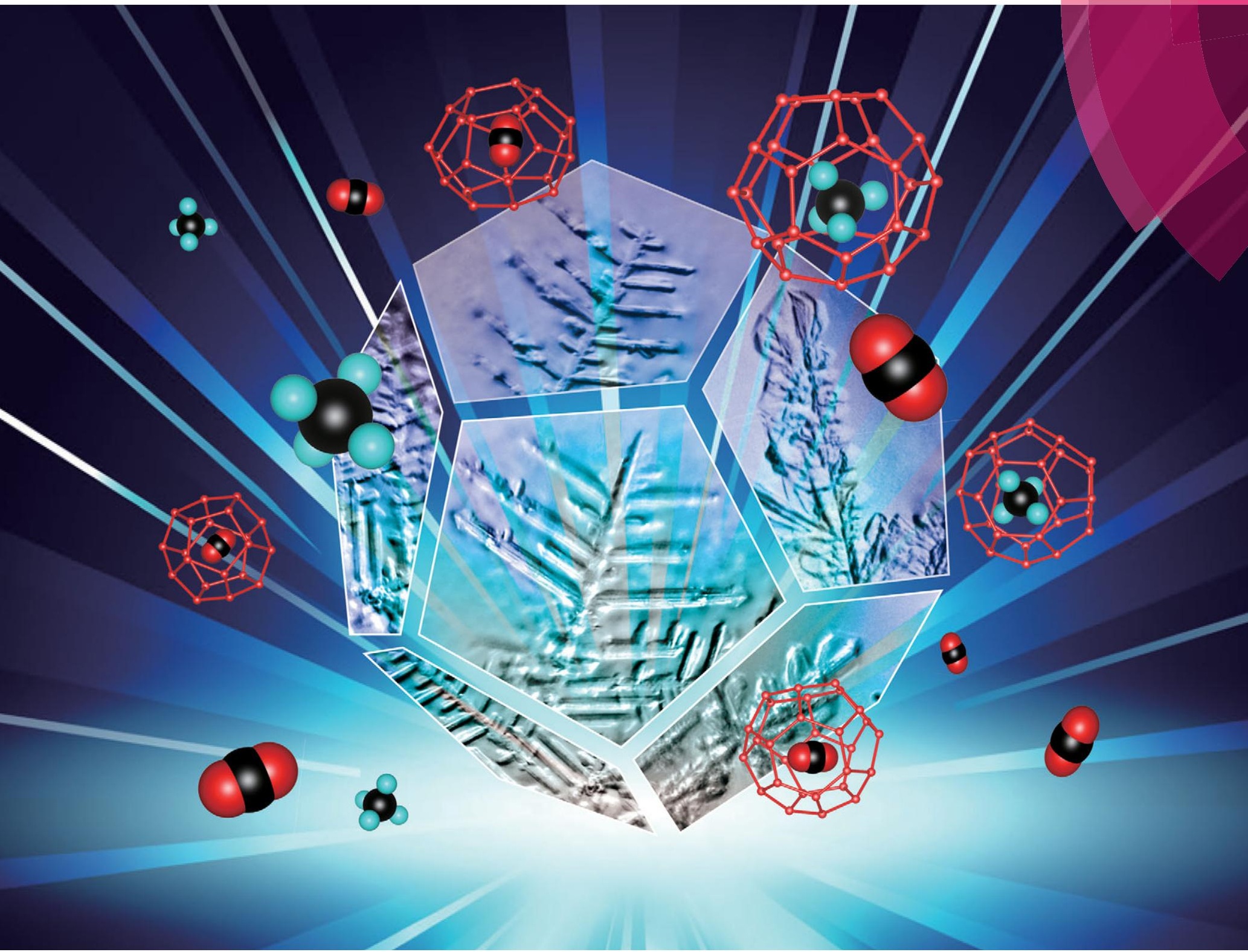

ISSN 1144-0546

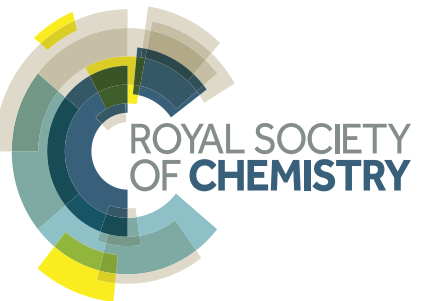




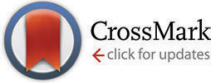

Cite this: New J. Chem., 2015, 39, 8254

Received (in Victoria, Australia) 1st May 2015,

Accepted 17th July 2015

DOI: $10.1039 / c 5 n j 01080 b$

www.rsc.org/njc

\title{
Crystal growth of clathrate hydrates formed with methane + carbon dioxide mixed gas at the gas/liquid interface and in liquid water
}

\author{
Hiroki Ueno, Hotaka Akiba, Satoru Akatsu and Ryo Ohmura*
}

\begin{abstract}
Visual observations of $\mathrm{CH}_{4}+\mathrm{CO}_{2}$ hydrate crystal growth formed at the gas/liquid interface and in liquid water presaturated with a mixed gas have been made. The compositions of the $\mathrm{CH}_{4}+\mathrm{CO}_{2}$ gaseous mixture were 40:60 and 30:70 for the gas/liquid interface observations, 30:70 and 70:30 for water saturated with the guest gas. The feed gas compositions of the $\mathrm{CH}_{4}$ and $\mathrm{CO}_{2}$ gaseous mixture were 40:60 and 30:70 for the gas/liquid interface observations, or 30:70 and 70:30 for liquid water. The crystal morphology of the $\mathrm{CH}_{4}+\mathrm{CO}_{2}$ hydrate observed in both feed gas compositions was similar. This may be ascribed to the fact that the molar ratios of $\mathrm{CO}_{2}$ to $\mathrm{CH}_{4}$ in the liquid phase ranged from $90: 10$ to $97: 3$ due to the greater solubility of $\mathrm{CO}_{2}$ in water. These results suggest that the crystal morphology of the $\mathrm{CH}_{4}+\mathrm{CO}_{2}$ hydrate may be controlled by the guest composition in the liquid phase, not by the feed gas composition. As the system subcooling increased, the shape of the hydrate crystals changed from polygons to sword-like or dendrites. The implications for the process design of the hydrate-based technologies are discussed based on the observations.
\end{abstract}

\section{Introduction}

Clathrate hydrates (hereafter hydrates) are crystalline solid compounds enclosing molecules called the "guest" in the cages consisting of hydrogen-bonded water molecules called the "host". Major properties of the hydrates are a large heat of formation/decomposition, large gas storage capacity and guestsubstance selectivity. The examples of technologies that use these properties of the hydrates are submarine/subterranean separation of $\mathrm{CO}_{2},{ }^{1-3}$ heat pump/refrigeration systems, ${ }^{4}$ storage media for natural gas ${ }^{5}$ and hydrogen, ${ }^{6}$ gas separation and extraction. $^{7}$

Unconventional natural gases, such as natural gas containing a high concentration of $\mathrm{CO}_{2},{ }^{8}$ bio-methane, ${ }^{9}$ coal bed methane ${ }^{10}$ and naturally-occurring methane hydrate,${ }^{11}$ are currently expected to become future energy sources. To use these unconventional natural gases, it is important to remove $\mathrm{CO}_{2}$ from these gases. As for the coal bed methane and the methane hydrate, several methods for extraction have been proposed. Recovering $\mathrm{CH}_{4}$ by injecting high pressure $\mathrm{CO}_{2}$ into the reservoir may be considered as one of the methods. ${ }^{12-14}$ The gas produced from the reservoir is

Department of Mechanical Engineering, Keio University, 3-14-1 Hiyoshi, Kohoku-ku, Yokohama 223-8522, Japan. E-mail: rohmura@mech.keio.ac.jp;

Fax: +81-45-566-1813; Tel: +81-45-566-1813

$\dagger$ Electronic supplementary information (ESI) available: The results of the formation and growth of $\mathrm{CH}_{4}+\mathrm{CO}_{2}$ or $\mathrm{CO}_{2}$ gas hydrate crystals at the gas/liquid interface. See DOI: $10.1039 / \mathrm{c} 5 \mathrm{nj} 01080 \mathrm{~b}$ likely to be the mixture of $\mathrm{CH}_{4}$ and $\mathrm{CO}_{2}$. Therefore there is a necessity to separate $\mathrm{CH}_{4}$ and $\mathrm{CO}_{2}$.

Chemical absorption, adsorption and membrane separation are the major separation technologies to separate $\mathrm{CH}_{4}$ and $\mathrm{CO}_{2}$. As an alternative technology, a gas separation method using clathrate hydrates has been examined. ${ }^{15,16}$ Various studies on $\mathrm{CH}_{4} /$ $\mathrm{CO}_{2}$ separation using clathrate hydrates have been reported. ${ }^{8,17-20}$

To apply the technologies using hydrates in industry, the knowledge of hydrate crystal morphology and crystal engineering principles are important. ${ }^{21}$ "Crystal morphology" is the geometric configuration of crystals such as their shapes and sizes. The crystal morphology has significant impacts on handling the formed hydrate in the engineering processes such as slurry pumping, dehydration/dewatering and storage of the hydrates.

In addition to the impacts in the industrial-plant scale, understanding the hydrate crystal morphology should find its significance in an even greater scale. When we consider the geological scale issue, the knowledge of the crystal morphology is important for the geological storage of $\mathrm{CO}_{2}$ and recovery of $\mathrm{CH}_{4} \cdot{ }^{22}$ When $\mathrm{CO}_{2}$ is injected into the methane hydrate reservoir to recover $\mathrm{CH}_{4}, \mathrm{CO}_{2}$ may be stored at the sea bottoms by replacement of $\mathrm{CH}_{4}$ with $\mathrm{CO}_{2}$. However, $\mathrm{CH}_{4}$ in the hydrates would not be completely replaced with $\mathrm{CO}_{2}$ and the hydrates containing $\mathrm{CH}_{4}$ and $\mathrm{CO}_{2}$ may be eventually formed. ${ }^{23}$ The morphology of hydrate crystals formed with $\mathrm{CH}_{4}+\mathrm{CO}_{2}$ mixed gas should affect the recovery of $\mathrm{CH}_{4}$ and the stability of $\mathrm{CO}_{2}$ storage for a long term. 
Clathrate hydrates generally grow at the guest gas/water interface under high-pressure and low-temperature conditions, and then the film of hydrate crystals cover the interface. If the water had been saturated with the guest gas beforehand, the hydrates grew into the liquid water in various morphologies such as dendrites, columns, etc. ${ }^{24-27}$

There are several observational studies that have reported the hydrate crystal morphology formed at the gas/liquid interface $^{28-32}$ and in the liquid water saturated with the guest gas. ${ }^{24-27}$ They revealed that the crystal morphology and the propagation rate of the hydrate film depended on driving force, such as the system subcooling $\Delta T_{\text {sub }}$, the difference of the system temperature from the gas-hydrate-water equilibrium temperature corresponding to the system pressure. Servio and Englezos ${ }^{29}$ observed the crystal morphology of either $\mathrm{CH}_{4}$ or $\mathrm{CO}_{2}$ hydrates formed on a water droplet. The driving force was defined as the difference of equilibrium and experimental pressures. They reported that the driving force had a significant effect on the crystal morphology and the size of a water droplet did not affect the induction time or the crystal morphology. Tanaka et al. ${ }^{30}$ and Saito et al. ${ }^{31}$ observed the morphology and the lateral film growth rate of $\mathrm{CH}_{4}, \mathrm{C}_{2} \mathrm{H}_{6}$, $\mathrm{C}_{3} \mathrm{H}_{8}$ and $\mathrm{CH}_{4}+\mathrm{C}_{2} \mathrm{H}_{6}+\mathrm{C}_{3} \mathrm{H}_{8}$ hydrate crystals. They revealed that the difference of pressure had no relation to the hydrate morphology. Ohmura et $a .^{24,25}$ reported the visual observations of the formation and growth of clathrate hydrate crystals in the liquid water presaturated with $\mathrm{CH}_{4}$ or $\mathrm{CO}_{2}$ gas. They correlated $\mathrm{CH}_{4}$ or $\mathrm{CO}_{2}$ hydrate morphology with non-dimensional index assuming mass transfer control of crystal morphology.

The morphologies of the hydrate crystals in the porous media were also reported. Tohidi et $a .^{33}$ observed the crystal growth of clathrate hydrates formed with dissolved $\mathrm{CO}_{2}$ or gaseous guest $\left(\mathrm{CH}_{4}, \mathrm{CH}_{4}+\mathrm{CO}_{2}\right.$ mixture, and natural gas) in the porous media systems. Katsuki et al. ${ }^{34,35}$ visually observed the growth and aging of $\mathrm{CH}_{4}$ or $\mathrm{CO}_{2}$ hydrate in a porous medium filled with the liquid water. They revealed that fine dendritic crystals changed into particulate crystals in the system with $\mathrm{CH}_{4}$ or $\mathrm{CO}_{2}$ gas at high $\Delta T_{\text {sub. At low }} \Delta T_{\text {sub }}$, the faceted hydrates formed and bridged the porous medium, however the morphological change was hardly identified.

As described above, there are several studies that report the morphology and the growth rate of the clathrate hydrates formed with $\mathrm{CH}_{4}, \mathrm{CO}_{2}$, etc. However, there is no observation report on the crystal morphology and the crystal growth rate of $\mathrm{CH}_{4}+\mathrm{CO}_{2}$ hydrates. In this paper we visually observed the formation and growth of hydrate crystals formed with $\mathrm{CH}_{4}+$ $\mathrm{CO}_{2}$ mixed gas at the gas/liquid interface and in the liquid water saturated with the guest gas. To compare with $\mathrm{CH}_{4}+\mathrm{CO}_{2}$ hydrates, the morphology and the lateral growth rate of $\mathrm{CO}_{2}$ hydrates are also observed.

\section{Experimental}

The fluid samples used in the experiments were deionized and distilled liquid water and $\mathrm{CH}_{4}+\mathrm{CO}_{2}$ mixture gas or $\mathrm{CO}_{2}$ gas. The conductivity of the water was less than $0.10 \mathrm{mS} \mathrm{m}^{-1}$.

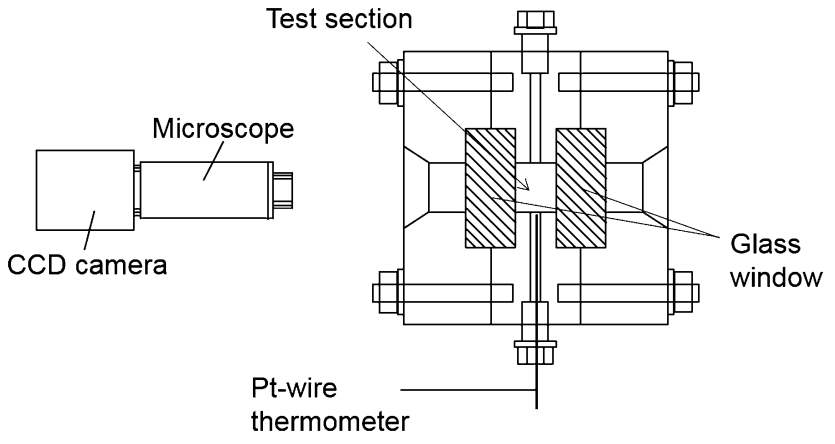

Fig. 1 Schematic illustration of the apparatus.

The compositions of the $\mathrm{CH}_{4}$ and $\mathrm{CO}_{2}$ gas mixture were 40:60 and 30:70 in the case of the gas/liquid interface, 30:70 and $70: 30$ in the water saturated with the guest gas. These compositions were determined by the assumption of the fuel gases containing many $\mathrm{CO}_{2}$ such as bio-methane and unconventional natural gas.

Fig. 1 schematically illustrates the main portion of the experimental apparatus. The test section holding hydrate crystals and the test fluids is a cylinder made of stainless steel. It measured $25 \mathrm{~mm}$ in diameter and $20 \mathrm{~mm}$ in axial length, provided with glass windows for internal observation. The temperature $T_{\mathrm{ex}}$ inside the test section was controlled by ethylene glycol aqueous solution in the jacket which covers the container and measured using a platinum resistance thermometer inserted from the container undersurface to directly under the stage. The pressure $P$ inside the test section was controlled by supplying the guest gas from a cylinder through a reducing valve and measured by a strain gauge pressure transducer. The uncertainty of a temperature measurement is $\pm 0.2 \mathrm{~K}$ and that of a pressure measurement is $\pm 0.02 \mathrm{MPa}$.

Fig. 2(a) is a view showing a frame format of the test section during the observation at the gas/liquid interface. A cylindrical Teflon stage with $6 \mathrm{~mm}$ diameter was installed in the test section, and a water droplet was held on this upper surface. Fig. 2(b) is a diagram of the test section during the observation in the liquid phase. Four cubic centimeters of the liquid water were poured into the test section to form a pool.

The air inside the cylinder was replaced with the guest gas by repeating the pressurization and evacuating it from the test section. $P$ was then set to a prescribed level as shown in Table 1.

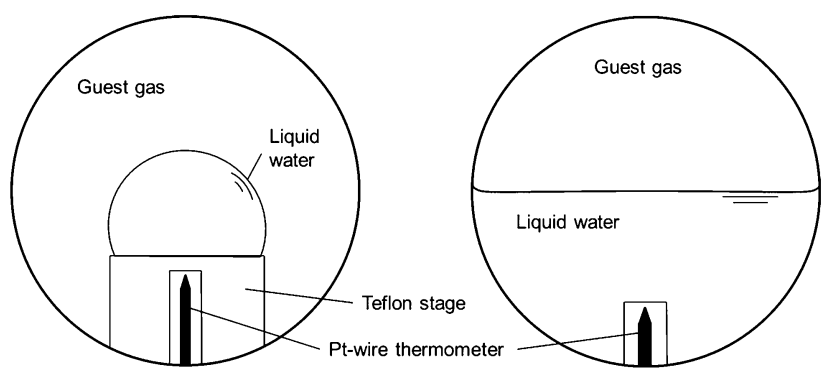

(a) the observation at gas-liquid interface (b) the observation in liquid water

Fig. 2 Schematic diagram of the test section. 
Table 1 Temperature and pressure conditions of the experiments with $\mathrm{CO}_{2}$ or $\mathrm{CH}_{4}+\mathrm{CO}_{2}$ mixed gas systems

\begin{tabular}{llll}
\hline The guest gas & Pressure $/ \mathrm{MPa}$ & $T_{\mathrm{eq}} / \mathrm{K}$ & $\Delta T_{\mathrm{sub}} / \mathrm{K}$ \\
\hline $\mathrm{CO}_{2}$ & 2.2 & 281.3 & $0.9-2.0$ \\
& 3.2 & 282.1 & $0.6-1.7$ \\
$\mathrm{CH}_{4}+\mathrm{CO}_{2}(40: 60)$ & 2.2 & 277.1 & $0.9-3.5$ \\
& 3.2 & 280.9 & $0.9-3.5$ \\
$\mathrm{CH}_{4}+\mathrm{CO}_{2}(30: 70)$ & 2.2 & 281.0 & $1.5-8.0$ \\
& 3.2 & 277.2 & $1.5-5.0$ \\
$\mathrm{CH}_{4}+\mathrm{CO}_{2}(70: 30)$ & 3.2 & 278.1 & $3.0-6.5$
\end{tabular}

$T$ was first decreased to about $265 \mathrm{~K}$ to form hydrates (and possibly simultaneously ice). Hydrates were decomposed by raising $T$ to a level higher by about $1.0 \mathrm{~K}$ than $T_{\text {eq }}$, the gaswater-hydrate three phase equilibrium temperature. $T_{\text {eq }}$ was first estimated using CSMGem, ${ }^{36}$ and then measured by a batch isochoric procedure. ${ }^{29}$ After visual verification of the decomposition of all hydrates, $T$ was set at the prescribed temperature $T_{\text {ex }}$ to observe the formation and growth of hydrate crystals. We applied this method to shorten the induction time for hydrate reformation by using the memory effect. ${ }^{37}$ The formation and growth of the hydrate crystals were observed and recorded using a CCD camera (Fortissimo, CMOS130-USB2) and a microscope (Edmund, model IUC-130CK2). We performed three or four experimental runs under the same conditions and confirmed the reproducibility of the crystal morphology and crystal growth behavior.

We defined the system subcooling $\Delta T_{\text {sub }}$ as the index of the driving force for the crystal growth. $\Delta T_{\text {sub }}$ is the difference of the system temperature from the triple gas-hydrate-water equilibrium temperature $\left(\Delta T_{\mathrm{sub}}=T_{\mathrm{eq}}-T_{\mathrm{ex}}\right)$. The lateral growth rates of the hydrate crystals formed on a water droplet exposed to the guest gas (the rate of two dimensional hydrate crystal growth) were measured from the optical observation records.

\section{Results and discussion}

\section{Formation and growth of $\mathrm{CH}_{4}+\mathrm{CO}_{2}$ or $\mathrm{CO}_{2}$ gas hydrate crystals on the droplet}

The sequential images of the hydrate crystals growing on a water droplet exposed to $\mathrm{CH}_{4}+\mathrm{CO}_{2}(40: 60)$ mixed gas or pure $\mathrm{CO}_{2}$ gas at different levels of $\Delta T_{\text {sub }}$ and the same pressure, $P=3.2 \mathrm{MPa}$, are shown in Fig. 3. The time shown under each picture is the elapsed time after the hydrate nucleation. As previously reported in the systems with water and hydrocarbon, ${ }^{30,31}$ hydrate nucleation first occurred at a random point on the water droplet, and then the hydrate crystals grew to form a polycrystalline layer covering the surface of the water droplet. The induction time ranged from $5 \mathrm{~min}$ to $3 \mathrm{~h}$ and the nucleation site also varied, such as the upper part of the water droplet, the side, etc. These nucleation phenomena agreed with the fact that the nucleation of hydrate crystals is stochastic. ${ }^{37}$ After the polycrystalline layer covered the water droplet, no remarkable crystal growth was visually observed.
As shown in Fig. 3, it took $412 \mathrm{~s}$ until the hydrate layer completely covered the water droplet at $\Delta T_{\text {sub }}=0.9 \mathrm{~K}$, while the elapsed time was $104 \mathrm{~s}$ at $\Delta T_{\text {sub }}=1.9 \mathrm{~K}$ in the system with $\mathrm{CH}_{4}+$ $\mathrm{CO}_{2}(40: 60)$ mixed gas. The time taken for the surface coverage by the hydrates was shorter with larger $\Delta T_{\text {sub }}$. This result indicated that the lateral growth rates of the hydrate crystals increased with increasing $\Delta T_{\text {sub. This tendency was also }}$ observed with a simple $\mathrm{CO}_{2}$ hydrate and a $\mathrm{CH}_{4}+\mathrm{CO}_{2}(30: 70)$ hydrate.

Fig. 4 indicates the magnified images of the hydrate crystals formed with $\mathrm{CH}_{4}+\mathrm{CO}_{2}$ mixed gas $(40: 60)$ at different levels of $\Delta T_{\text {sub }}$ and $P$. The frames of the red lines in the images highlight the individual hydrate crystals. The highlighted crystals were typical ones in three or four experimental runs under the same conditions. All images in this figure were recorded just after the hydrate film completely covered the water droplet. From Fig. 4, we can find that the crystal morphology depended on $\Delta T_{\text {sub }}$. The size of individual hydrate crystals increased and the shape changed from sword-like to polygons with decreasing $\Delta T_{\text {sub. }}$. For the mixed gas $(40: 60)$ system at 3.2 and $2.2 \mathrm{MPa}$ (shown in Fig. 4), the shape of the hydrate crystals was sword-like or elongated polygonal with a length of $0.05-0.3 \mathrm{~mm}$ at $\Delta T_{\text {sub }}>$ $1.5 \mathrm{~K}$, and the crystal shape changed to polygonal with a size of $0.5-1.5 \mathrm{~mm}$ at $\Delta T_{\text {sub }}=0.9 \mathrm{~K}$. The magnified images of the hydrate crystals formed with $\mathrm{CH}_{4}+\mathrm{CO}_{2}$ mixed gas (30:70) and pure $\mathrm{CO}_{2}$ gas are shown in Fig. S1 and S2 (ESI $\dagger$ ). The dependence of crystal morphology on $\Delta T_{\text {sub }}$ at $P=2.2 \mathrm{MPa}$ was the same as that at $P=3.2 \mathrm{MPa}$. The compositions of the $\mathrm{CH}_{4}+\mathrm{CO}_{2}$ gas mixture had also no significant influence on the crystal morphology of $\mathrm{CH}_{4}+\mathrm{CO}_{2}$ hydrates.

We arrange the observational results of the crystal morphology of $\mathrm{CH}_{4}, \mathrm{CO}_{2}$ and $\mathrm{CH}_{4}+\mathrm{CO}_{2}$ hydrates along $\Delta T_{\text {sub }}$ in Fig. 5. At a given $\Delta T_{\text {sub }}$, the individual crystal size of the $\mathrm{CH}_{4}+\mathrm{CO}_{2}(40: 60$ or 30 : 70) hydrate or the $\mathrm{CO}_{2}$ hydrate was smaller than that of the $\mathrm{CH}_{4}$ hydrate. The size of the $\mathrm{CH}_{4}+\mathrm{CO}_{2}$ hydrate crystal was almost the same as that of the $\mathrm{CO}_{2}$ hydrate at a given $\Delta T_{\text {sub }}$.

Fig. 6 shows the relation between the lateral growth rate of hydrate crystals and $\Delta T_{\text {sub }}$. The lateral growth rate is defined as the peripheral length of the water droplet from the bottom to the apex divided by the time required for covering the surface completely. With increasing $\Delta T_{\text {sub }}$ or the system pressure, the hydrate film growth rate increased in all the systems. The lateral growth rate of the hydrate was increased with increasing concentration of $\mathrm{CO}_{2}$ in the feed gas. The growth rate of the $\mathrm{CO}_{2}$ hydrate film was higher than those of $\mathrm{CH}_{4}, \mathrm{CH}_{4}+\mathrm{CO}_{2}$ hydrate films, and the growth rate of the $\mathrm{CH}_{4}+\mathrm{CO}_{2}$ hydrate was between those of $\mathrm{CO}_{2}$ and $\mathrm{CH}_{4}$ hydrates.

\section{Formation and growth of $\mathrm{CH}_{4}+\mathrm{CO}_{2}$ hydrate crystals in the liquid water with a flat interface}

Fig. 7 shows the sequential images of the formation and growth of hydrate crystals formed in the liquid water presaturated with the $\mathrm{CH}_{4}+\mathrm{CO}_{2}$ (30:70) gas mixture at $3.2 \mathrm{MPa}$ and different $\Delta T_{\text {sub }}$ Fig. S3 also shows those with the $\mathrm{CH}_{4}+\mathrm{CO}_{2}(30: 70)$ gas mixture at 2.2 $\mathrm{MPa}$ (ESI $\dagger$ ). The initial nucleation of hydrate crystals mainly occurred at the gas/liquid interface. The thin 


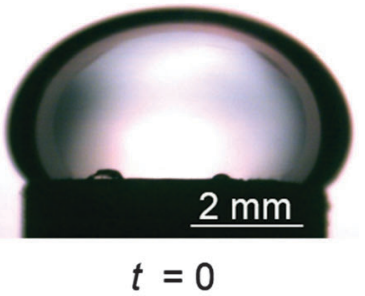

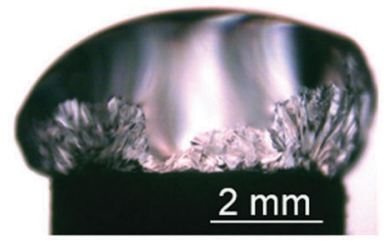

$t=250 \mathrm{~s}$

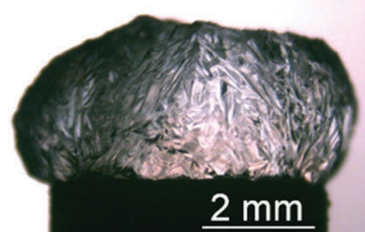

$t=412 \mathrm{~s}$

(a) $\mathrm{CH}_{4}+\mathrm{CO}_{2}(40: 60)$ hydrate $P=3.26 \mathrm{MPa}, \Delta T_{\text {sub }}=0.9 \mathrm{~K}$

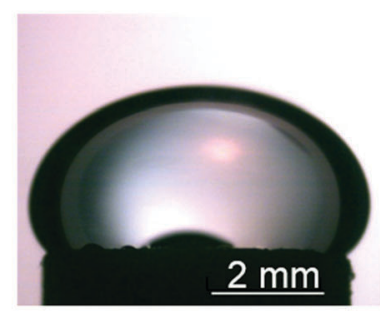

$t=0$

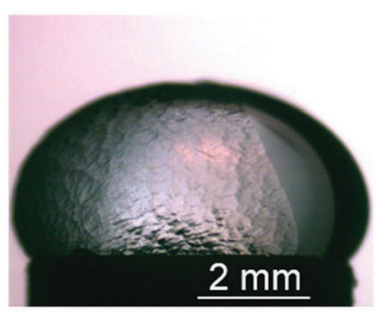

$t=60 \mathrm{~s}$

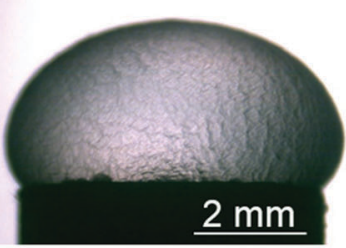

$t=104 \mathrm{~s}$

(b) $\mathrm{CH}_{4}+\mathrm{CO}_{2}(40: 60)$ hydrate, $P=3.23 \mathrm{MPa}, \Delta T_{\text {sub }}=1.9 \mathrm{~K}$

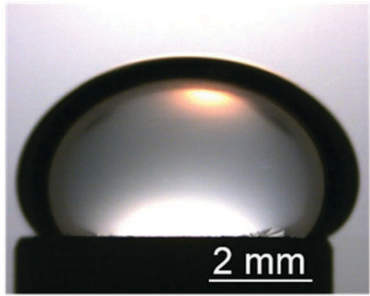

$t=0$

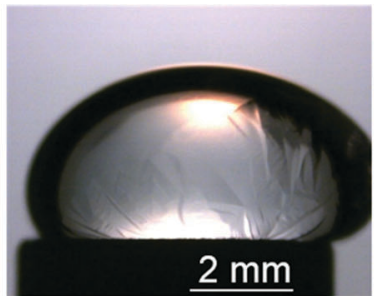

$t=110 \mathrm{~s}$

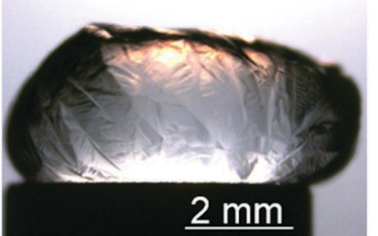

$t=157 \mathrm{~s}$

(c) $\mathrm{CO}_{2}$ hydrate, $P=3.30 \mathrm{MPa}, \Delta T_{\text {sub }}=0.8 \mathrm{~K}$

Fig. 3 Sequential images of the hydrate crystals growing on a water droplet exposed to $\mathrm{CH}_{4}+\mathrm{CO}_{2}(40: 60)$ mixed gas or $\mathrm{CO}_{2}$ simple gas at different levels of $\Delta T_{\text {sub. }}$

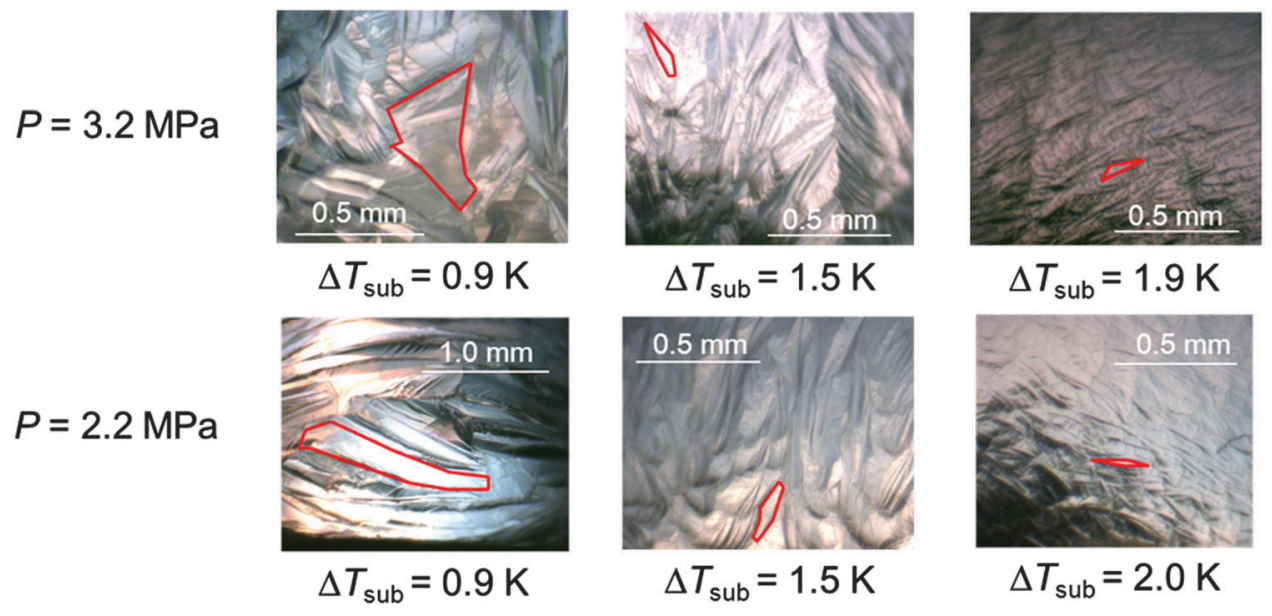

Fig. 4 Classification of $\mathrm{CH}_{4}+\mathrm{CO}_{2}(40: 60)$ hydrate crystal morphology based on $\Delta T_{\text {sub }}$.

hydrate film grew to cover the gas/liquid interface, and the hydrate crystals subsequently grew into the liquid water. However, infrequently, the hydrate crystals first formed in the liquid phase when $\Delta T_{\text {sub }}>5.0 \mathrm{~K}$. This result may be ascribed to a memory effect remaining at the bottom of the reactor. The memory effect is a phenomenon that the induction time of 


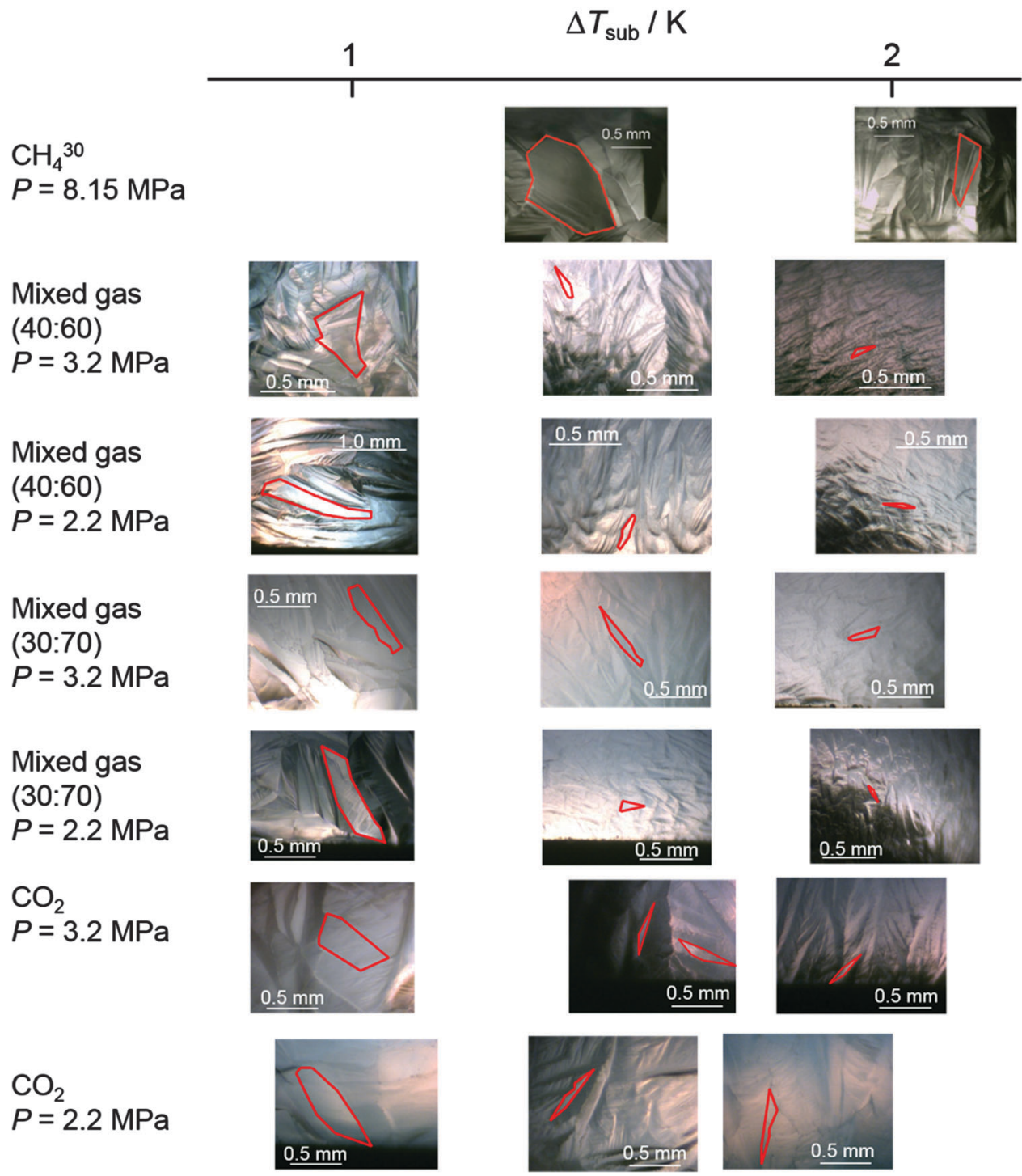

Fig. 5 Arrangement and comparison of hydrate crystal observations depending on $\Delta T_{\text {sub. }}$.

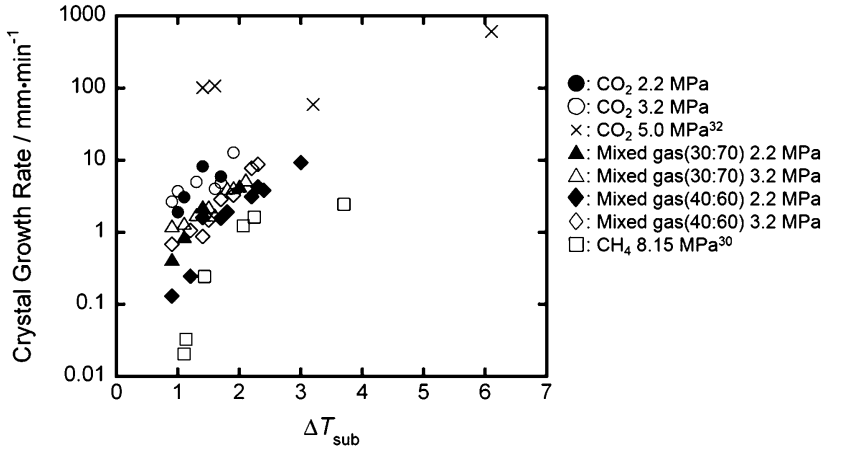

Fig. 6 Crystal growth rates at the guest gas/liquid interface.

hydrate re-formation is much shorter than that of the initial formation. The hydrate dissociation occurred at the bottom of the reactor since the density of the $\mathrm{CH}_{4}+\mathrm{CO}_{2}$ hydrate was greater than that of the liquid water. Therefore the memory remained at the bottom would promote the nucleation of hydrates and the hydrate crystals formed initially in the liquid phase. In the present study, the time that we visually observed hydrate nucleation was defined as $t=0$.

Two types of hydrate crystal growth were observed in the liquid water. When hydrate crystals formed at the bottom of the reactor, the hydrates grew from the bottom to the liquid phase. On the other hand, when the hydrate crystals formed in the bulk of the liquid water, the hydrates fell down to the bottom of the reactor and then grew to the liquid phase. This process of hydrate formation and growth was commonly observed in all the systems.

As shown in Fig. 7, polygonal crystals grew at the bottom of the reactor in an hour or two after the hydrate film covered the gas/liquid interface at $\Delta T_{\text {sub }}=3.0 \mathrm{~K}$. When $\Delta T_{\text {sub }}=4.0 \mathrm{~K}$, we observed the growth of dendritic crystals in the liquid water. The dendritic crystals initially grew in a few tens of minutes and then the shapes of the side branches changed from dendrites to polygonal. At $\Delta T_{\mathrm{sub}}=6.0 \mathrm{~K}$, the dendrite crystals grew in the 


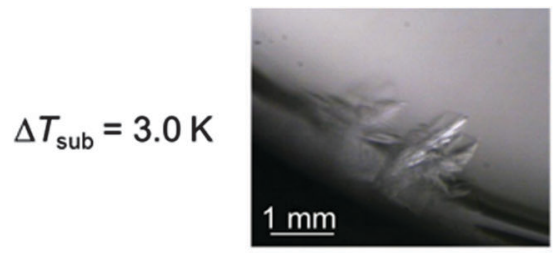

$t=52.7 \mathrm{~min}$

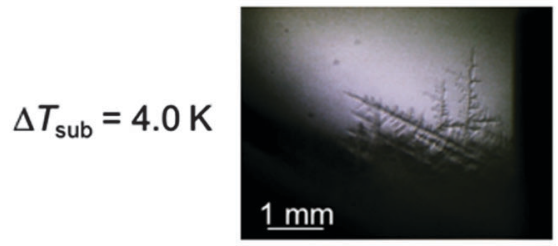

$t=2.8 \mathrm{~min}$

$\Delta T_{\text {sub }}=6.0 \mathrm{~K}$

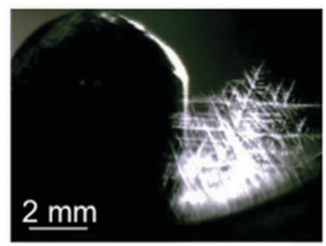

$t=0.5 \mathrm{~min}$

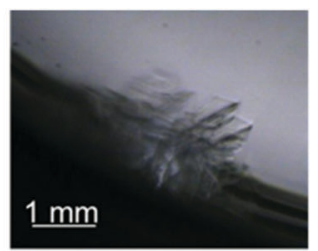

$t=61.5 \mathrm{~min}$

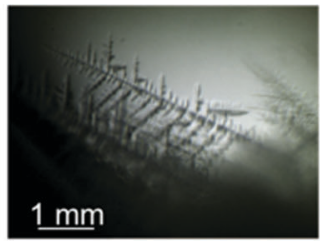

$t=9.7 \mathrm{~min}$

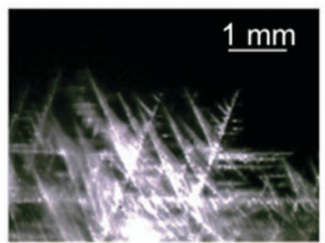

$t=1.3 \mathrm{~min}$

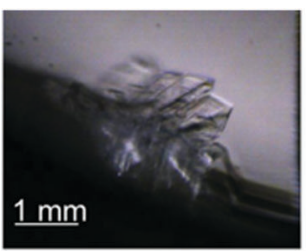

$t=119 \mathrm{~min}$

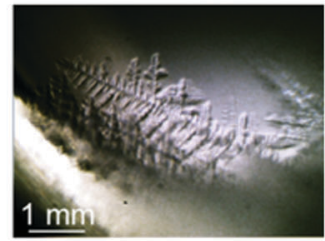

$t=13.1 \mathrm{~min}$

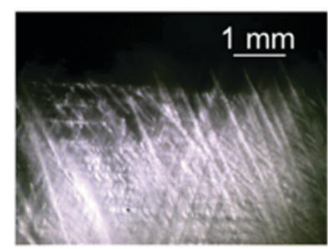

$t=4.3 \mathrm{~min}$

Fig. 7 Difference in hydrate growth depending on $\Delta T_{\text {sub }}$ [mixed gas $(30: 70)$ system, $P=3.2 \mathrm{MPa}$ ]

liquid water and the morphological change in the shapes of the side branches was not observed. No hydrate was observed at $\Delta T_{\text {sub }}<1.5 \mathrm{~K}$. With increasing system pressure, the amount of hydrate crystals increased at a given $\Delta T_{\text {sub }}$. This may be ascribed to the increase in the amount of dissolved guest gas with increasing pressure. As shown in Fig. 7 and Fig. S3 (ESI $\dagger$ ), the dependence of crystal morphology on $\Delta T_{\text {sub }}$ at $P=2.2 \mathrm{MPa}$ was the same as that at $P=3.2 \mathrm{MPa}$ in the system with $30: 70$ mixed gases.

Observational results in the system with mixed gas $(70: 30)$ at three different levels of $\Delta T_{\text {sub }}$ and at $P=3.2 \mathrm{MPa}$ are presented in Fig. 8. No hydrate was observed at $\Delta T_{\text {sub }}<3.0 \mathrm{~K}$. When

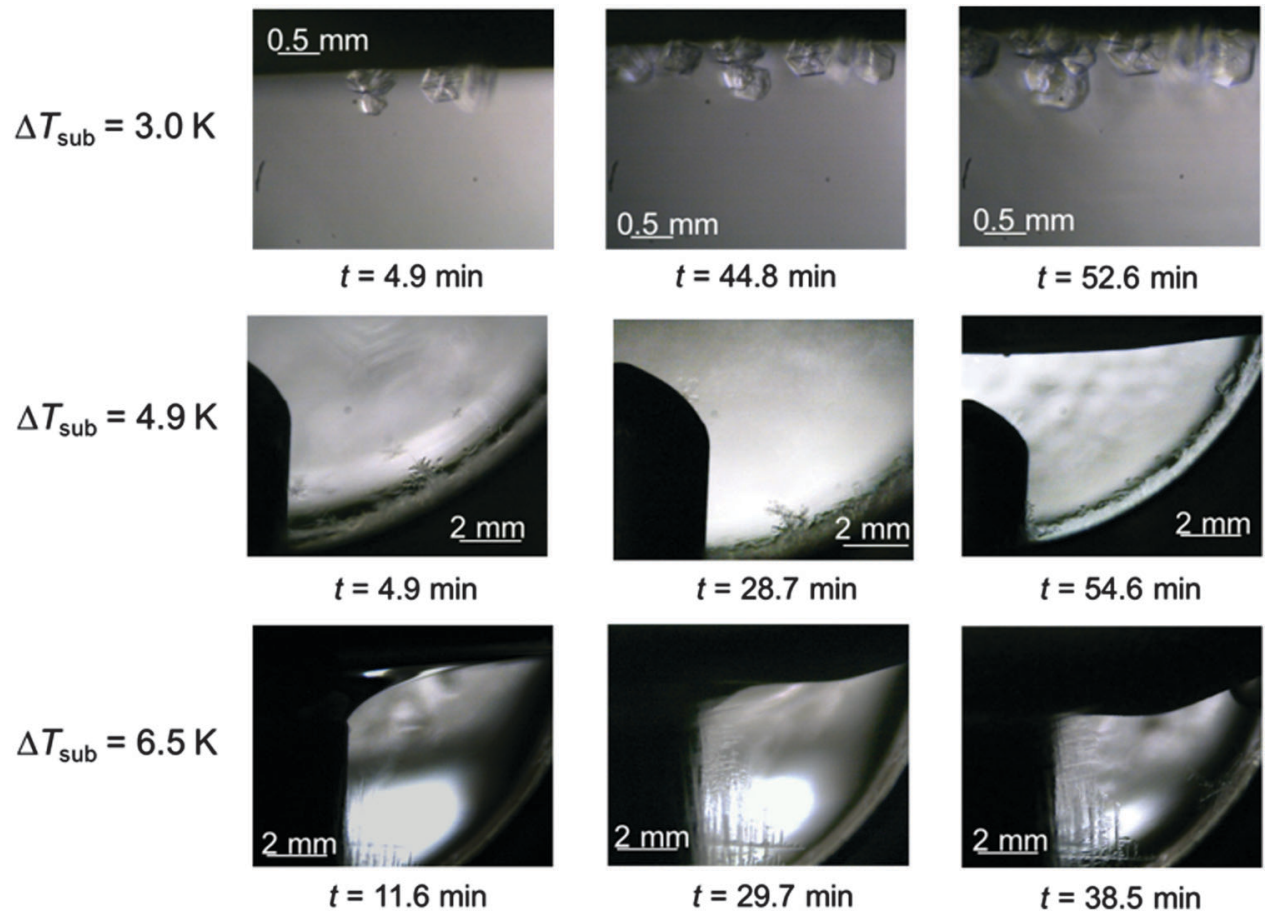

Fig. 8 Difference in hydrate growth depending on $\Delta T_{\text {sub }}$ [mixed gas $(70: 30)$ system, $P=3.2 \mathrm{MPa}$ ] 


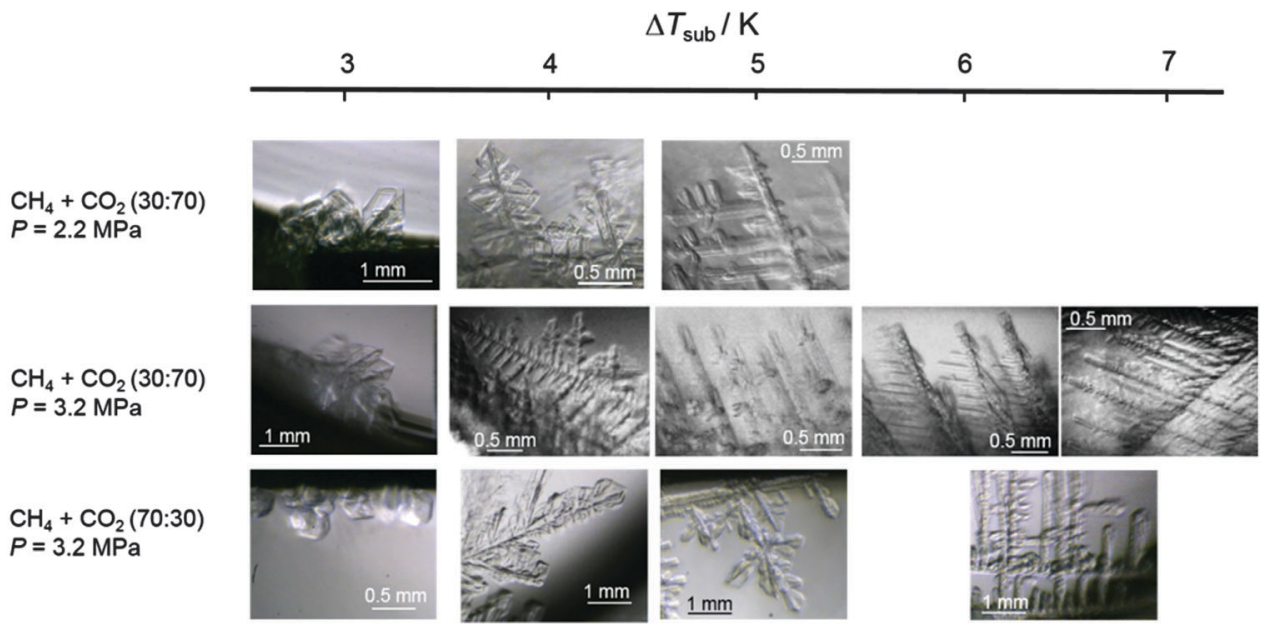

Fig. 9 Comparison of hydrate crystal morphology observations depending on $\Delta T_{\text {sub }}$.

$\Delta T_{\text {sub }}=3.0 \mathrm{~K}$, the hydrate crystals floated up and attached to the hydrate film, then grew to be polygonal crystals. At $\Delta T_{\text {sub }}>$ $4.9 \mathrm{~K}$, the hydrates sank and grew at the bottom of the reactor. The dendritic crystals grew in the liquid water and the shapes of side branches changed from dendrites to polygons in an hour or two. Floating up and settling down of $\mathrm{CH}_{4}+\mathrm{CO}_{2}$ hydrate crystals in the liquid water were observed depending on $\Delta T_{\text {sub }}$ and this indicates that the densities of $\mathrm{CH}_{4}+\mathrm{CO}_{2}$ $(70: 30)$ hydrate crystals and the water saturated with the guest gas may be almost the same under these thermodynamic conditions.

From these results, it is concluded that $\mathrm{CH}_{4}+\mathrm{CO}_{2}$ hydrate crystal morphologies formed in the liquid water varied depending on $\Delta T_{\text {sub }}$. The crystal shape changed from polygons to dendrites with increasing $\Delta T_{\text {sub }}$. The arrangements and comparisons of hydrate crystal observations in the system with $\mathrm{CH}_{4}+\mathrm{CO}_{2}(30: 70$ or $70: 30$ ) mixed gas are shown in Fig. 9. In all the systems, the hydrate crystal shape was polygonal with a size of $0.3-1.0 \mathrm{~mm}$ at $\Delta T_{\text {sub }}<4.0 \mathrm{~K}$. When $4.0 \mathrm{~K}<\Delta T_{\text {sub }}<5.0 \mathrm{~K}$, the shape of the hydrate crystal was dendrite. The shape of side branches changed from dendrites to polygons. At $\Delta T_{\text {sub }}>5.0 \mathrm{~K}$, the dendritic crystals grew in the liquid water. In the present study, the difference in the composition of $\mathrm{CH}_{4}+\mathrm{CO}_{2}$ mixed gas had little influence on crystal morphology. These results may be ascribed to the water solubility of $\mathrm{CH}_{4}$ and $\mathrm{CO}_{2}$ and discussed in the next section "Effect of the guest gas composition in the liquid water".

Fig. 10 shows sequential images of the morphological changes due to aging, observed in the system with the $\mathrm{CH}_{4}+$ $\mathrm{CO}_{2}$ (30:70) gas mixture, $P=2.2 \mathrm{MPa}$. The morphological changes of $\mathrm{CH}_{4}+\mathrm{CO}_{2}(30: 70,70: 30)$ hydrates at $P=3.2 \mathrm{MPa}$ are shown in Fig. S4 and S5 (ESI $\dagger$ ). At $\Delta T_{\text {sub }}>4.0 \mathrm{~K}$, the crystal morphology of the hydrate crystals changed from dendrites to particulates in several to tens hours. From these results, it is expected that the morphology of the $\mathrm{CH}_{4}+\mathrm{CO}_{2}$ hydrate formed by $\mathrm{CO}_{2}$ injection to recover $\mathrm{CH}_{4}$ may change due to aging of several hours.

The comparison of the size of the hydrate crystals and the particles in the hydrate-bearing sediments may be related to the

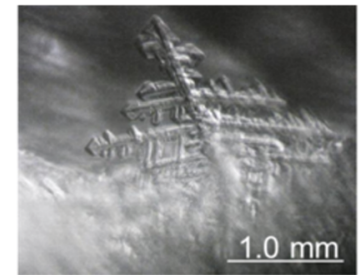

$t=0.44 \mathrm{~h}$

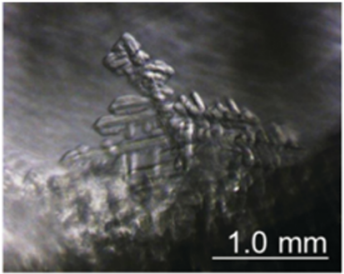

$t=18.6 \mathrm{~h}$ $\Delta T_{\text {sub }}=4.4 \mathrm{~K}$

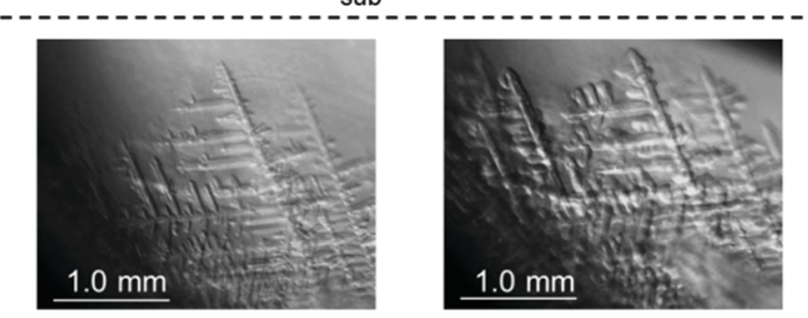

$t=0.16 \mathrm{~h}$

$t=20.2 \mathrm{~h}$

$$
\Delta T_{\text {sub }}=5.0 \mathrm{~K}
$$

Fig. 10 Sequential images of the morphological changes in the system with the $\mathrm{CH}_{4}+\mathrm{CO}_{2}(30: 70)$ gas mixture, $P=2.2 \mathrm{MPa}$.

mechanical stability of the sediments. Naturally-occurring methane hydrates are found in sand, silt and clay. The size of the pore spaces of the marine sediments are estimated to be approximately 1-100 $\mu \mathrm{m}$. The size of $\mathrm{CH}_{4}+\mathrm{CO}_{2}$ hydrate crystals observed in the present study was greater than $0.3 \mathrm{~mm}$. It is then inferred that the size of $\mathrm{CH}_{4}+\mathrm{CO}_{2}$ hydrates is larger than that of the pore spaces in the hydrate-bearing sediments.

\section{Effect of the guest gas composition in the liquid water}

The observations in the present study show no significant difference in the crystal morphology of the hydrates formed with $\mathrm{CH}_{4}+\mathrm{CO}_{2}$ mixed gas at the gas/liquid interface as well as in the liquid water regardless of the system pressure and the mixed gas composition. These results may be ascribed to the differences in the water solubility of $\mathrm{CH}_{4}$ and $\mathrm{CO}_{2}$. The solubility 
Table 2 The differences in the molar ratio of the gas phase and liquid phase under water-hydrate-vapor equilibrium conditions depending on the pressure and gas composition calculated using the CSMGem program, corresponding to the water-to-vapor molar ratio in the experimental apparatus

\begin{tabular}{llll}
\hline $\begin{array}{l}\text { The molar ratio } \\
\text { of initial gas }\left(\mathrm{CH}_{4}: \mathrm{CO}_{2}\right)\end{array}$ & Pressure/MPa & $\begin{array}{l}\text { The molar ratio of gas phase } \\
\text { at the equilibrium conditions }{ }^{a}\left(\mathrm{CH}_{4}: \mathrm{CO}_{2}\right)\end{array}$ & $\begin{array}{l}\text { The molar ratio of liquid phase } \\
\text { at the equilibrium } \text { conditions }^{a}\left(\mathrm{CH}_{4}: \mathrm{CO}_{2}\right)\end{array}$ \\
\hline $40: 60$ & 2.2 & $42.8: 57.2$ & $2.8: 97.2$ \\
& 3.2 & $43.3: 56.7$ & $3.0: 97.0$ \\
$30: 70$ & 2.2 & $32.4: 67.6$ & $1.8: 98.2$ \\
& 3.2 & $33.0: 67.0$ & $2.0: 98.0$ \\
$70: 30$ & 3.2 & $73.0: 27.0$ & $9.6: 90.4$
\end{tabular}

${ }^{a}$ The inner volume of the test cell and liquid water was $9800 \mathrm{~mm}^{3}$ and $4000 \mathrm{~mm}^{3}$, respectively.

of $\mathrm{CO}_{2}$ in the liquid water was approximately 30 times higher than that of $\mathrm{CH}_{4}$ at a given $P-T$ condition. It was estimated that much more $\mathrm{CO}_{2}$ dissolved in the liquid water than $\mathrm{CH}_{4}$.

Table 2 presents the $\mathrm{CH}_{4}+\mathrm{CO}_{2}$ molar ratio of the gas phase and the liquid phase under the water-hydrate-vapor three phase equilibrium conditions under the system pressure. These data were calculated using the CSMGem program, corresponding to the water-to-vapor molar ratio in the experimental apparatus. The inner volume of the test cell and liquid water was $9800 \mathrm{~mm}^{3}$ and $4000 \mathrm{~mm}^{3}$, respectively. Therefore the molar of water in the system was 40 times higher than that of gas at 2.2 $\mathrm{MPa}$ and 30 times higher at $3.2 \mathrm{MPa}$ in the calculation conditions of CSMGem. The deviations of the data predicted by CSMGem from the previous experimental data were calculated to be predominantly within $\pm 4 \%$, at worst within $\pm 15 \%$ at the temperatures from $274 \mathrm{~K}$ to $286 \mathrm{~K}$, pressures from $0.5 \mathrm{MPa}$ to 9.1 MPa for $\mathrm{CH}_{4},{ }^{38}$ within $\pm 7 \%$, at worst within $\pm 10 \%$ from $273 \mathrm{~K}$ to $286 \mathrm{~K}, 0.1 \mathrm{MPa}$ to $10.1 \mathrm{MPa}$ for $\mathrm{CO}_{2} \cdot{ }^{39}$

From Table 2, the molar ratios of the gas phase under the thermodynamic equilibrium conditions depended on the pressure and the compositions of the feed gas. However, the molar ratios of $\mathrm{CO}_{2}$ to $\mathrm{CH}_{4}$ in the liquid phase under the thermodynamic equilibrium conditions ranged from 90:10 to 97:3 due to the differences in the water solubility of $\mathrm{CH}_{4}$ and $\mathrm{CO}_{2}$. These data may explain that no differences in hydrate crystal morphology with gas compositions were observed. From these results, it is inferred that the guest gas composition in the liquid phase would be the controlling factor for the crystal growth of $\mathrm{CH}_{4}+\mathrm{CO}_{2}$ hydrates. The crystal growth characteristics depending on the guest composition in the liquid phase should be taken into account for the process design of the hydrate-based $\mathrm{CH}_{4} / \mathrm{CO}_{2}$ separation.

\section{Conclusion}

The formation and growth of $\mathrm{CH}_{4}+\mathrm{CO}_{2}$ hydrate crystals formed at the gas/liquid interface and in the liquid water have been observed. The crystal growth of the $\mathrm{CO}_{2}$ hydrate at the gas/ liquid interface was also observed for comparison. The feed gas compositions of $\mathrm{CH}_{4}$ and the $\mathrm{CO}_{2}$ gas mixture were $40: 60$ and $30: 70$ for the gas/liquid interface observations, or $30: 70$ and $70: 30$ for the liquid water. The crystal morphology of the $\mathrm{CH}_{4}+$ $\mathrm{CO}_{2}$ hydrate observed in both feed gas compositions was similar. This may be ascribed to the molar ratio of $\mathrm{CO}_{2}$ to $\mathrm{CH}_{4}$ in the liquid phase. The molar ratios of $\mathrm{CO}_{2}$ to $\mathrm{CH}_{4}$ in the liquid phase under the thermodynamic equilibrium conditions ranged from 90:10 to $97: 3$ due to greater solubility of $\mathrm{CO}_{2}$ in water. These results suggest that the crystal morphology of the $\mathrm{CH}_{4}+\mathrm{CO}_{2}$ hydrate may be controlled by the guest composition dissolved in the liquid phase, not on the feed gas composition.

The hydrate initially formed at the gas/liquid interface. The thin hydrate film grew to cover the gas/liquid interface, and then the hydrate crystals subsequently grew into the liquid phase. The morphology and the growth rate of the hydrate crystal varied with $\Delta T_{\text {sub. }}$. The size of the hydrate crystals decreased and the lateral growth rate increased with increasing $\Delta T_{\text {sub }}$. As $\Delta T_{\text {sub }}$ increased, the shape of the individual hydrate crystals changed from polygons to sword-like or dendrites. The morphology of $\mathrm{CH}_{4}+\mathrm{CO}_{2}$ hydrate crystals in the liquid water changed from dendrites to particulates due to aging when $\Delta T_{\text {sub }}>4.0 \mathrm{~K}$.

\section{Conflict of interest}

The authors declare no competing financial interest.

\section{Acknowledgements}

This study was supported by a Keirin-racing-based researchpromotion fund from the JKA Foundation and by JSPS KAKENHI Grant Number 25289045.

\section{References}

1 R. Ohmura and Y. H. Mori, Environ. Sci. Technol., 1998, 32, 1120-1127.

2 P. G. Brewer, E. Peltzer, I. Aya, P. Haugan, R. Bellerby, K. Yaname, R. Kojima, P. Waltz and Y. J. Nakajima, J. Oceanogr., 2004, 60, 751-758.

3 P. G. Brewer, C. Friederich, E. T. Peltzer and F. M. Orr, Science, 1999, 284, 943-945.

4 T. Ogawa, T. Ito, K. Watanabe, K. Tahara, R. Hiraoka, J. Ochiai, R. Ohmura and Y. H. Mori, Appl. Therm. Eng., 2006, 26, 2157-2167.

5 Y. H. Mori, Chin. J. Chem. Eng., 2003, 54, 1-17.

6 W. L. Mao and H. Mao, Proc. Natl. Acad. Sci. U. S. A., 2004, 101, 708-710. 
7 Y. T. Seo, I. L. Moudravski, J. A. Ripmeester, J. W. Lee and H. Lee, Environ. Sci. Technol., 2005, 39, 2315-2319.

8 M. V. Denderen, E. Ineke and M. Golombok, Ind. Eng. Chem. Res., 2009, 48, 5802-5807.

9 D. Zhang, A. Li, Y. Cui, W. Song and W. Lin, Ind. Eng. Chem. Res., 2011, 50, 8742-8749.

10 E. Ryckebosch, M. Drouillon and H. Vervaeren, Biomass Bioenergy, 2011, 35, 1633-1645.

11 M. Ota, K. Morohashi, Y. Abe, M. Watanabe, R. L. Smith Jr. and H. Inomata, Energy Convers. Manage., 2005, 46, 1680-1691.

12 D. Zhang, S. Li, Y. Cui, W. Song and W. Lin, Ind. Eng. Chem. Res., 2011, 50, 8742-8749.

13 H. Lee, Y. Seo, Y. T. Seo, I. L. Moudrakaovski and J. A. Ripmeester, Angew. Chem., Int. Ed., 2003, 42, 5048-5051.

14 K. Ohgaki, K. Takano, H. Sangawa, T. Matsubara and S. Nakano, J. Chem. Eng. Jpn., 1996, 29, 478-483.

15 P. Linga, A. Adeyemo and P. Englezos, Environ. Sci. Technol., 2007, 42, 315-320.

16 S. Li, S. Fan, J. Wang, X. Lang and Y. J. Wang, Chem. Eng. Data Ser., 2010, 55, 3212-3215.

17 J. M. Herri, A. Bouchemoua, M. Kwaterski, A. Fezoua, Y. Ouabbas and A. Camerio, Fluid Phase Equilib., 2011, 301, 171-190.

18 N. Dabrowski, C. Windmeier and L. R. Oellrich, Energy Fuels, 2009, 23, 5603-5610.

19 H. Y. Acosta, P. R. Bishnoi and M. A. Clark, J. Chem. Eng. Data, 2011, 56, 69-73.

20 N. Mayofi, D. Dalmazzone, W. Furst, A. Delahaye and L. Fournaison, J. Chem. Eng. Data, 2010, 55, 1271-1275.

21 K. Shin, I. Moudrakovski, M. D. Davari, S. Alavi, C. I. Ratcliffe and J. A. Ripmeester, CrystEngComm, 2014, 16, 7209-7217.

22 K. Z. House, D. P. Schrag, C. F. Harvey and K. S. Lackner, Proc. Natl. Acad. Sci. U. S. A., 2006, 103, 12291-12295.

23 C. M. White, D. H. Smith, K. L. Jones, A. L. Goodman, S. A. Jikich, R. B. Lacount, S. B. Dubose, E. Ozgemir,
B. I. Morsi and K. T. Schroeder, Energy Fuels, 2005, 19, 659-724.

24 R. Ohmura, W. Shimada, T. Uchida, Y. H. Mori, S. Takeya, J. Nagao, H. Minagawa, T. Ebinuma and H. Narita, Philos. Mag., 2004, 84, 1-16.

25 R. Ohmura, S. Matsuda, T. Uchida, T. Ebinuma and H. Narita, Cryst. Growth Des., 2005, 5, 953-957.

26 R. Ohmura, T. Shigetomi and Y. H. Mori, J. Cryst. Growth, 1999, 196, 164-173.

27 J. D. Lee, M. Song, R. Susilo and P. Englezos, Cryst. Growth Des., 2006, 6, 1428-1439.

28 E. M. Freer, M. S. Selim and E. D. Sloan Jr., Fluid Phase Equilib., 2001, 185, 65-75.

29 P. Servio and P. Englezos, AIChE J., 2003, 49, 269-276.

30 R. Tanaka, R. Sakemoto and R. Ohmura, Cryst. Growth Des., 2009, 9(5), 2529-2536.

31 K. Saito, M. Kishimoto, R. Tanaka and R. Ohmura, Cryst. Growth Des., 2010, 11, 295-301.

32 T. Uchida, T. Ebinuma, J. Kawabata and H. Narita, J. Cryst. Growth, 1999, 204, 348-356.

33 B. Tohidi, R. Anderson, M. B. Clennell, R. W. Burgass and A. B. Biderkab, Geology, 2001, 29, 867.

34 D. Katsuki, R. Ohmura, T. Ebinuma and H. Narita, Philos. Mag., 2006, 86, 1753-1761.

35 D. Katsuki, R. Ohmura, T. Ebinuma and H. Narita, Philos. Mag., 2007, 87, 1057-1069.

36 E. D. Sloan Jr., C. A. Koh, CSMGem, a phase-equilibrium calculation program package accompanying the following book: E. D. Sloan Jr. and C. A. Koh, Clathrate Hydrates of Natural Gases, 3rd edn, CRC Press, Boca Raton, FL, 2007.

37 R. Ohmura, M. Ogawa, K. Yasuoka and Y. H. Mori, J. Phys. Chem. B, 2003, 107, 5289-5293.

38 K. Lekvam and P. R. Bishnoi, Fluid Phase Equilib., 1997, 131, 297-309.

39 W. S. Dodds, L. F. Stutzman and B. J. Sollami, Ind. Eng. Chem., 1956, 1, 92-95. 